Table 1. Radiographic and clinical features of the examined patients

\begin{tabular}{|l|l|l|l|l|l|}
\hline & CPPD & $\begin{array}{l}\text { Seropositive RA } \\
\mathrm{N}=181\end{array}$ & $\begin{array}{l}\text { Seronegative RA } \\
\mathrm{N}=142\end{array}$ & $\begin{array}{l}\text { Gout } \\
\mathrm{N}=30\end{array}$ & $\begin{array}{l}\mathrm{PMR} \\
\mathrm{N}=30\end{array}$ \\
\hline \%women & 77,8 & 76,2 & 75,3 & 28,1 & 44,1 \\
\hline Mean age (years) & $73,8 \pm 9,8$ & $58,8 \pm 13,0$ & $58,9 \pm 14,7$ & $56,6 \pm 14,7$ & $65,7 \pm 8,9$ \\
\hline Symptom duration (years) & $0,3 \pm 0,7$ & $0,4 \pm 0,7$ & $0,4 \pm 0,9$ & $1.0 \pm 3,0$ & $0,4 \pm 1,7$ \\
\hline $\begin{array}{l}\text { Chondrocalcinosis (radiography, } \\
\text { \%) }\end{array}$ & 93,0 & 35,7 & 34,6 & 12,5 & 11,8 \\
\hline Erosions (radiography, \%) & 50,8 & 42,9 & 32,1 & 50 & 8,8 \\
\hline Clinical involvement of hands (\%) & 83,2 & 76,2 & 72,8 & 25 & 50 \\
\hline Clinical involvement of feet (\%) & 24,3 & 33,3 & 32,1 & 62,5 & 11,8 \\
\hline Clinical involvement of knee (\%) & 42,7 & 39,3 & 42 & 59,4 & 32,4 \\
\hline Symmetric arthritis (\%) & 64,6 & 67,9 & 74 & 65,6 & 44,1 \\
\hline Acute attacks, sudden onset (\%) & 60,5 & 40,5 & 40,7 & 65,6 & 38,2 \\
\hline $\begin{array}{l}\text { Both diagnoses RA and CPPD in } \\
\text { record (\%) }\end{array}$ & 27,6 & 29,7 & 32,1 & 6,25 & 14,7 \\
\hline $\begin{array}{l}\text { Therapy with MTX or another } \\
\text { csDMARD (\%) }\end{array}$ & 13,0 & 52,4 & 42,0 & 3,1 & 23,5 \\
\hline $\begin{array}{l}\text { Therapy with } \\
\text { Hydroxychloroquine (\%) }\end{array}$ & 7,0 & 4,8 & 7,4 & 0 & 0 \\
\hline Therapy with Colchicine (\%) & 43,8 & 9,5 & 9,9 & 75 & 5,9 \\
\hline
\end{tabular}

Conclusion: There were a lot of similarities but also some important differences between patients with CPPD and RA with no major differences between seropositive and seronegative RA. Of interest, radiographic chondrocalcinosis was seen in more than a third of RA patients. Importantly, clinical symmetry of arthritis and involvement of hands did not differentiate between CPPD and RA, mainly the acuteness of attacks did. Co-occurrence of both diseases was frequently observed. There was no major difference between seropositive and seronegative RA.

REFERENCES:

[1] Rosenthal AM, Ryan LM. N Engl J Med. 2016

Disclosure of Interests: None declared.

DOI: 10.1136/annrheumdis-2021-eular.3660

\section{POS1146 NONCODING RNA CONTRIBUTE TO PATHOGENESIS IN PRIMARY GOUTY ARTHRITIS}

Q. B. Zhang ${ }^{1}$, Y. Q. Huang ${ }^{1}$, F. N. Xiao', G. L. Jian ${ }^{1}$, Y. P. Tang ${ }^{2}$, F. Dai ${ }^{2}$, J. X. Zheng ${ }^{2}$, Y. F. Qing ${ }^{2}{ }^{1}$ The Affiliated Hospital of North Sichuan Medical College, Geriatrics, Nanchong, Sichuan, China; ${ }^{2}$ The Affiliated Hospital of North Sichuan Medical College, Rheumatology and Immunology, Nanchong, Sichuan, China

Background: Gout is an arthritic disease caused by the deposition of monosodium urate crystal (MSU) in the joints, which can lead to acute inflammation and damage adjacent tissue [1].Over the past decade, noncoding RNAs (ncRNAs) have been shown to have crucial importance in health and disease[2,3]. However, studies evaluating the function of ncRNAs in gout are scarce, and current knowledge of the role of ncRNAs in gout is still limited.

Objectives: To assess the contribution of noncoding RNAs to gout and the clinical importance of these genes in primary gouty arthritis (GA).

Methods: The mRNA expression levels of noncoding RNAs (LINC00173, LINC00963, LINC01330 and miRNA-182-5p) were measured in peripheral blood mononuclear cells (PBMCs) from 60 gout patients(including 30 acute gout patients, 30 intercritical gout patients) and 40 healthy subjects. The relationship between noncoding RNA expression levels and laboratory features was analyzed in GA patients.

Results: The expression levels of LINC00173, LINC00963 and miRNA-182-5p were much lower in the $A G$ and $I G$ group than in the $H C$ groups $(p<0.05)$, and no significant difference was detected between $A G$ and $I G$ groups $(P>0.05)$. The expression levels of LINC01330 were much lower in the AG group than in the IG and $H C$ groups $(p<0.05)$, and no significant difference was detected between $A G$ and IG groups $(P>0.05)$. In $G A$ patients, the levels of noncoding RNAs mRNA correlated with laboratory inflammatory and metabolic indexes.

Conclusion: Altered noncoding RNAs expression suggests that noncoding RNAs is involved in the pathogenesis of GA and participates in regulating inflammation and metabolism.

REFERENCES:

[1] Xu Yi-Ting,Leng Ying-Rong,Liu Ming-Ming et al. MicroRNA and long noncoding RNA involvement in gout and prospects for treatment.[J].Int Immunopharmacol, 2020, 87: 106842.doi:10.1016/j.intimp.2020.106842

[2] Yu Yunfang,Zhang Wenda,Li Anlin et al. Association of Long Noncoding RNA Biomarkers With Clinical Immune Subtype and Prediction of Immunotherapy Response in Patients With Cancer.[J].JAMA Netw Open, 2020, 3: e202149. doi:10.1001/jamanetworkopen.2020.2149
[3] Zou Yaoyao,Xu Siqi,Xiao Youjun et al. Long noncoding RNA LERFS negatively regulates rheumatoid synovial aggression and proliferation.[J].J Clin Invest, 2018, 128: 4510-4524.doi:10.1172/JCI97965 c

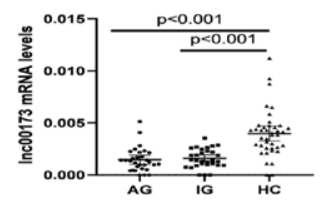

c

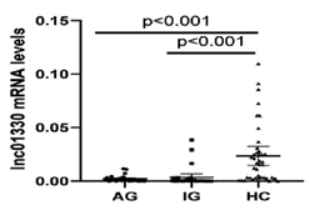

b

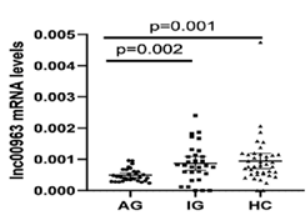

d

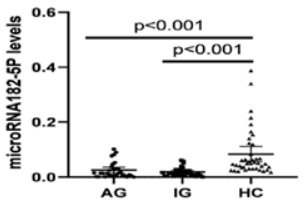

Figure 1. Relative Expression of noncoding RNAs in the PBMCs of Patients

Disclosure of Interests: Quan-Bo Zhang Grant/research support from: the National Natural Science Foundation of China(General Program) (no.81974250) and Science and Technology Plan Project of Sichuan Province (no.2018JY0257), Yu-Qin Huang: None declared, Fan-Ni Xiao: None declared, gui-lin jian: None declared, Yi-Ping Tang: None declared, Fei Dai: None declared, Jian-Xiong Zheng: None declared, Yu-Feng Qing Grant/research support from: Science and Technology Project of Nanchong City (no.18SXHZ0522).

DOI: 10.1136/annrheumdis-2021-eular.4056

\section{POS1147 COSTS AND FACTORS AFFECTING HEALTH SERVICE UTILISATION IN PATIENTS WITH GOUT: A LONGITUDINAL, POPULATION-LEVEL LINKED DATA STUDY IN WESTERN AUSTRALIA}

E. Kelty ${ }^{1}$, J. Nossent ${ }^{2}$, W. Raymond ${ }^{2}$, P. Robinson ${ }^{3}$, C. Hill ${ }^{4}$, C. Inderjeeth ${ }^{2}$, D. Preen ${ }^{1}, \underline{\text { H. Keen }}{ }^{2}$ on behalf of WARDER. ${ }^{1}$ UWA, School of Population \& Global Health, Perth, Australia; ${ }^{2}$ UWA, School of Medicine, Perth, Australia; ${ }^{3} U Q$, School of Medicine, Brisbane, Australia; ${ }^{4}$ University of Adelaide, School of Medicine, Adelaide, Australia

Background: Evidence suggests that gout is associated with high health care costs and that many inpatient admissions are preventable (1). Understanding the driver of health care costs will allow more targeted intervention.

Objectives: To examine factors associated with high health service utilisation and cost in patients admitted to hospital with gout, using whole-population linked hospital, WA cancer registration, Emergency Department (ED) and death data (2)

Methods: The study included patients (18 to 84 years) who had been admitted to hospital with a primary or co-diagnosis of gout for the first time between 1 Jan 02 and 31 Dec 09 Hospital costs were calculated per patient using DRG codes and ED costs were calculated from URG codes. Costs are presented in Australian dollars. Follow-up was completed at five years post their initial gout hospitalisation, at death, or at the 31th of December 2014. Both univariable and multivariable analysis was conducted for each patient characteristic. Independent variables were assessed for collinearity. Collinearity was assumed present where the correlation co-efficient was greater than 0.7 .

Results: 4,379 individuals were included. In the following five years, there was 22,222 ED attendances (median cost, \$1826 per patient (IQR: \$433 - \$4,414)), and 58,920 hospital admissions, (median cost, \$25,009 per patient (IQR $\$ 6,844-\$ 60,535)) .4,059$ (18.3\%) ED attendances and 3,834 (6.5\%) hospital admissions were potentially preventable. Gout was not a major driver of events, with $341(1.5 \%)$ ED attendances and 620 (1.1\%) hospital admissions coded with a primary diagnosis of gout. In the univariable analysis (Table 1), Aboriginality and smoking were associated with an increased number of both ED attendances and hospital admissions. Increased socio-economic status was associated with a reduction in ED attendances, however, this was not reflected in hospital admissions.

Conclusion: Patients admitted to hospital with gout are highly likely to be re-admitted or attend ED in the following 5 years. Many of these contacts are preventable, but are usually driven by comorbidities rather than gout.

REFERENCES:

[1] Loh K, . Intern Med J. 2020 Mar;50(3):386.

[2] https://www.datalinkage-wa.org.au. 